\title{
Arc Characteristics and Weld Bead Microstructure of Ti-6Al-4V Titanium Alloy in Ultra-high Frequency Pulse Gas Tungsten Arc Welding (UHFP-GTAW) Process
}

\author{
Wei LI ${ }^{1}$, Gaochong LV ${ }^{1}$, Qiang WANG ${ }^{2}$, Songtao HUANG ${ }^{1}$ * \\ ${ }^{1}$ Department of Electrical Engineering, Beijing Institute of Petrochemical Technology, No. 19 Qingyuan North Road, \\ Huangcun Town, Daxing District, Beijing 102617, China \\ ${ }^{2}$ China Aerospace Science and Industry Group Second Research Institute, Beijing 100854, China \\ crossref http://dx. doi. org/10.5755/j01.ms.26.4.22329
}

Received 19 December 2018; accepted 15 March 2019

\begin{abstract}
To resolve the problem of grain coarsening occurring in the fusion zone and the heat-affected zone during conventional gas tungsten arc welding(C-GTAW) welded titanium alloy, which severely restricts the improvement of weld mechanical properties, welding experiments on Ti-6Al-4V titanium alloy by adopting ultra-high frequency pulse gas tungsten arc welding (UHFP-GTAW) technique were carried out to study arc characteristics and weld bead microstructure. Combined with image processing technique, arc shapes during welding process were observed by highspeed camera. Meanwhile the average arc pressure under various welding parameters were obtained by adopting pressure measuring equipment with high-precision. In addition, the metallographic samples of the weld cross section were prepared for observing weld bead geometry and microstructure of the fusion zone. The experimental results show that, compared with C-GTAW, UHFP-GTAW process provides larger arc energy density and higher proportion of arc core region to the whole arc area. Moreover, UHFP-GTAW process has the obviously effect on grain refinement, which can decrease the grain size of the fusion zone. The results also revealed that a significant increase of arc pressure while increasing pulse frequency of UHFP-GTAW, which could improve the depth-to-width ratio of weld beads.

Keywords: Ti-6Al-4V, ultra-high frequency pulse GTAW, arc behavior, grain refinement, basket-weave structure.
\end{abstract}

\section{INTRODUCTION}

Because of excellent comprehensive properties of high specific strength, well corrosion resistance and small density, titanium alloys have been widely used as important metal structural materials in various fields such as aerospace, transportation and medical treatment [1-5]. Gas tungsten arc welding (GTAW) process is a preferred method for welding of titanium alloys due to its expedient operability and low cost [6]. However, the problem of grain coarsening occurring in the fusion zone and the heataffected zone severely restrict the improvement of weld mechanical properties during the GTAW process welded titanium alloy [7]. For obtaining grain refinement in weld fusion zones and improving the mechanical properties, pulsed current had been applied in GTAW process during past several decades [8-10]. It has been confirmed that introducing pulse current into the welding arc would exert remarkable influence on arc pressure, geometry of molten pool and the distribution of temperature field. Recently research results have also shown that, compared with conventional gas tungsten-arc welding (C-GTAW) process, pulsed gas tungsten-arc welding (P-GTAW) process has remarkable effect of refining grain size due to its lower heat input requirements and other advantages $[8,11]$. There were also some results confirming that pulsed current frequency had a significant impact on the refinement of weld grain, and higher pulse frequency could get better effect on grain refinement [12-14].

\footnotetext{
* Corresponding author. Tel. : +86-10-81292758; fax: +86-10-81292758.

E-mail address: liweijpu@sohu.com (S.T. Huang)
}

In order to take the advantage of high-frequency pulse current as efficiently as possible, ultra-high frequency pulse GTAW (UHFP-GTAW) technique in which pulsed current frequency is up to $80 \mathrm{kHz}$ has been developed to achieve better welding performance [15]. Previous research has proved that larger electromagnetic force help to increase weld penetration and higher central temperature of the molten pool in the weld bead can be obtained from UHFP-GTAW process [16]. In addition, with the implementation of related experiments on several metals including stainless steel, aluminum alloy and titanium alloy, ultra-high frequency pulsed current modulation of welding arc was proved to be effective on the crystallization process of the metal, and it is gradually confirmed that pulsed current with a frequency exceeding $20 \mathrm{kHz}$ have special effects on some aspects such as compressing arc shape, increasing weld penetration, refining grains and so on [17].

Arc behavior would exert directly impact on weld geometry and microstructure of weld seams, and then affect mechanical properties of weld bead. Considering that Ti-6Al-4V is the most commonly used titanium alloy, and in UHFP-GTAW process its weld quality is closely related to grain refinement degree, experimental research on arc behaviors and weld microstructures of Ti-6Al-4V titanium alloy by adopting UHFP-GTAW process were conducted to verify the validity of UHFP-GTAW process on grain refining. 


\section{METHODS}

\subsection{UHFP-GTAW technique}

Based on parallel-connected circuit topology as shown in Fig. 1, the welding power source can achieve ultra-high frequency pulsed current output with frequency up to $80 \mathrm{kHz}$. Base current inverter and pulse current inverter can all produce corresponding constant current outputs named $I_{\mathrm{b}}$ and $I_{\mathrm{pp}}$ respectively, and $I_{\mathrm{pp}}$ is equivalent to the difference value between peak current $I_{\mathrm{p}}$ and base current $I_{\mathrm{b}}$. The output effect of ultra-high frequency pulsed current depends on the fast alternation actions of two IGBTs (Insulated Gate Bipolar Transistor) named TP1 and TP2 at a certain frequency. The working principle is as follows: when $\mathrm{TP}_{1}$ turns on and $\mathrm{TP}_{2}$ off, the power source only provides base current $I_{\mathrm{b}}$ output; while $\mathrm{TP}_{1}$ turns off and $\mathrm{TP}_{2}$ on, the power source produces peak current $I_{\mathrm{p}}$ output. In particular, it should be noted that change rate of pulsed current rising and falling edges can reach $50 \mathrm{~A} / \mu \mathrm{s}$ by taking appropriate protection and absorption measures. Actual welding current waveform is shown in Fig. 2.

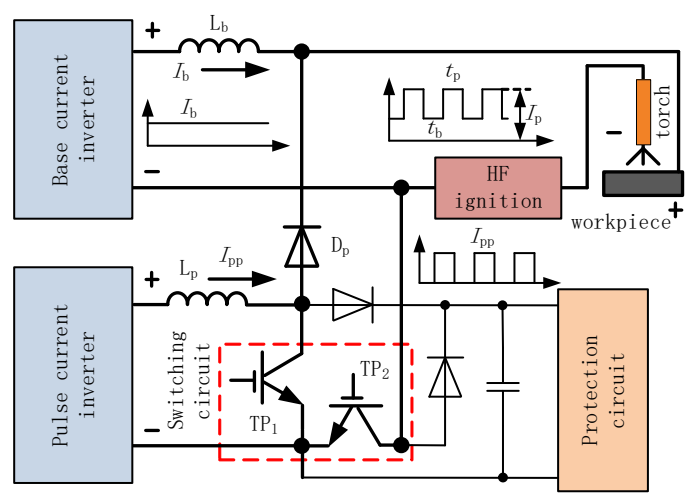

Fig. 1. Circuit topology of UHFP-GTAW power source

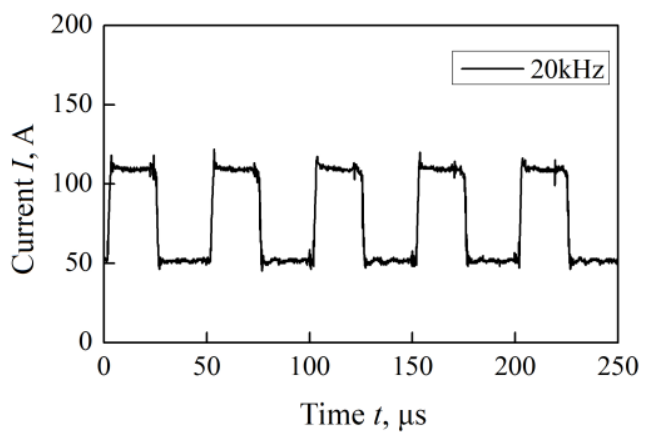

Fig. 2. Actual welding current waveform at frequency of $20 \mathrm{kHz}$

\subsection{Arc profile capture}

As shown in Fig. 3, a high-speed camera system is applied to capture arc profile, in which optical filters are employed to weaken the intensity of arc lights and protect camera lens. For ensuring arc stability and keeping focal length fixed during the welding process, workpiece moves in direction $\mathrm{Y}$ while welding torch and camera must be kept stationary. Arc profile captured by above means can be transferred to computer through communication cable.

The base metal used in this investigation is a high strength titanium alloy of $\mathrm{Ti}-6 \mathrm{Al}-4 \mathrm{~V}$ and the chemical composition (wt.\%) of the base metal is presented in
Table 1. Sheets of Ti-6Al-4V titanium alloy were cut into required sizes $(100 \mathrm{~mm} \times 50 \mathrm{~mm} \times 5 \mathrm{~mm})$.

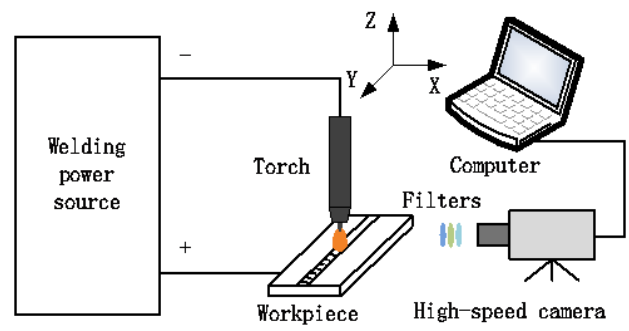

Fig. 3. Sketch of arc profile capture system

Table 1. Chemical composition (wt.\%) of Ti-6Al-4V

\begin{tabular}{|l|l|l|l|l|l|l|l|}
\hline $\mathrm{Al}$ & $\mathrm{V}$ & $\mathrm{N}$ & $\mathrm{C}$ & $\mathrm{H}$ & $\mathrm{O}$ & $\mathrm{Fe}$ & $\mathrm{Ti}$ \\
\hline 5.82 & 3.99 & 0.023 & 0.083 & 0.0007 & 0.063 & $<0.05$ & Balanace \\
\hline
\end{tabular}

Before welding all the workpieces were sanded firstly, and then cleaned by alcohol. The shielding gas was argon with the purity of $99.99 \%$ and the electrode with diameter of $2.4 \mathrm{~mm}$ is made up of $2 \%$ cerium and $98 \%$ tungsten. The distance between electrode and workpiece is $4 \mathrm{~mm}$ which was the arc length during welding. Welding current parameters are illustrated in Table 2 , in which $f, I_{\mathrm{b}}, I_{\mathrm{p}}, I_{\mathrm{m}}$ respectively represents pulse frequency, base current, peak current and mean current. Meanwhile other parameters are kept fixed as follows: gas flow rate is $12 \mathrm{~L} / \mathrm{min}$, welding speed is $60 \mathrm{~mm} / \mathrm{min}$ and duty cycle of pulse current is $50 \%$.

Table 2. Welding parameters

\begin{tabular}{|c|c|c|c|c|}
\hline No. & $f, \mathrm{kHz}$ & $I_{\mathrm{b}}, \mathrm{A}$ & $I_{\mathrm{p}}, \mathrm{A}$ & $I_{\mathrm{m}}, \mathrm{A}$ \\
\hline 1 & - & 60 & - & 60 \\
\hline 2 & 20 & 40 & 80 & 60 \\
\hline 3 & 40 & 40 & 80 & 60 \\
\hline 4 & - & 80 & - & 80 \\
\hline 5 & 20 & 50 & 110 & 80 \\
\hline 6 & 40 & 50 & 110 & 80 \\
\hline
\end{tabular}

\subsection{Image processing}

The bell-shaped photos captured were processed according to the procedures illustrated in Fig. 4 to obtain distinct boundaries. Original photo was initially converted into gray-scale map, and then areas outside arc column were removed from gray-scale map. The gray-scale map which only retains the arc column area was subsequently re-colored by using surface plot tool and contrast enhancement tool of the software called Image-Pro Plus. Post-processed arc column area was divided into three regions, where the red part is identified as arc core region I with the highest temperature, and the others as outer region II. The arc of core region I possessed the most concentrated plasma and the largest current density. The region I's area $\left(S_{\mathrm{I}}\right)$ and the region II's area $\left(S_{\mathrm{II}}\right)$, as well as projection diameter $\left(D_{\mathrm{I}}\right)$ of core region I were calculated through the software mentioned above.

\subsection{Arc force measurement}

As shown in Fig. 5 arc force measurement device is composed of a supporting mechanism with favorable rigidity and a precision electronic balance with accuracy of $0.01 \mathrm{~g}$. 

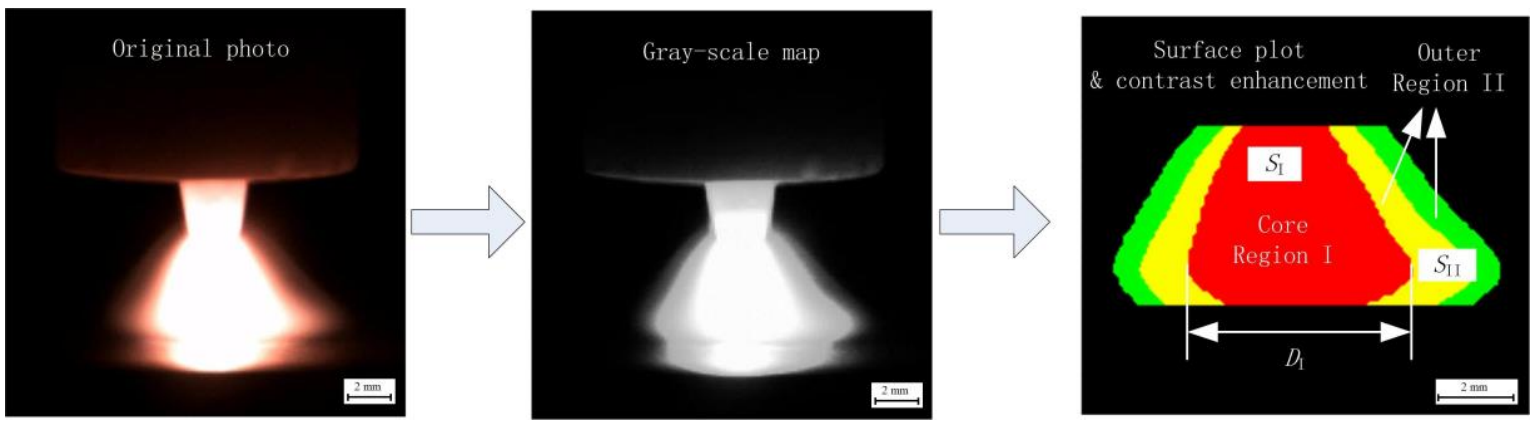

Fig. 4. Image processing steps

Workpiece is loaded on the top surface of insulated board to ensure electrical isolation with electronic balance. The pallet center of electronic balance should be kept consistent with that of insulated board, where arc force was measured and recorded for at least three times at each set of parameters shown in the Table 3. The validity of measurement results was ensured by means of taking average values from multiple measurements.

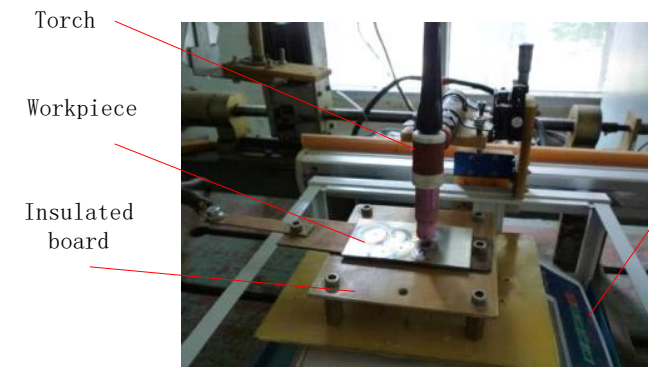

Electronic balance

Fig. 5. Arc force measurement device

Table 3. Welding current parameters for arc force measuring

\begin{tabular}{|c|c|c|c|c|c|}
\hline No. & $f, \mathrm{kHz}$ & $\Delta, \%$ & $I_{\mathrm{b}}, \mathrm{A}$ & $I_{\mathrm{p}}, \mathrm{A}$ & $I_{\mathrm{m}, \mathrm{A}}$ \\
\hline 1 & - & - & 60 & - & 60 \\
\hline 2 & 5 & 50 & 40 & 80 & 60 \\
\hline 3 & 10 & 50 & 40 & 80 & 60 \\
\hline 4 & 20 & 50 & 40 & 80 & 60 \\
\hline 5 & 40 & 50 & 40 & 80 & 60 \\
\hline
\end{tabular}

\section{RESULTS AND DISCUSSION}

\subsection{Arc profile}

Photographs obtained during welding process corresponding to the various set of parameters listed in Table 2 were shown in Fig. 6. Table 4 shows the experimental results reflecting arc shape, among which the area ratio $\left(R_{\mathrm{I}}\right)$ of region $\mathrm{I}$ to the whole region which manifests the variation of arc profile was obtained directly by calculation, and the others were achieved according to the method of image processing introduced in Section 2. 3.

As shown in the first three rows of Table 4, under the condition of average current $I_{\mathrm{m}}$ of $60 \mathrm{~A}$, the core area accounts for $38.9 \%$ of the whole arc column area by C-GTAW process, and whereas in UHFP-GTAW mode, the proportion increases to $39.8 \%$ and $40.6 \%$ respectively with the pulse frequency of $20 \mathrm{kHz}$ and $40 \mathrm{kHz}$. When average current enhanced to $80 \mathrm{~A}$, the same trend also can be observed. Fig. 7 illustrates the variation trend of $R_{\mathrm{I}}$ more intuitively.

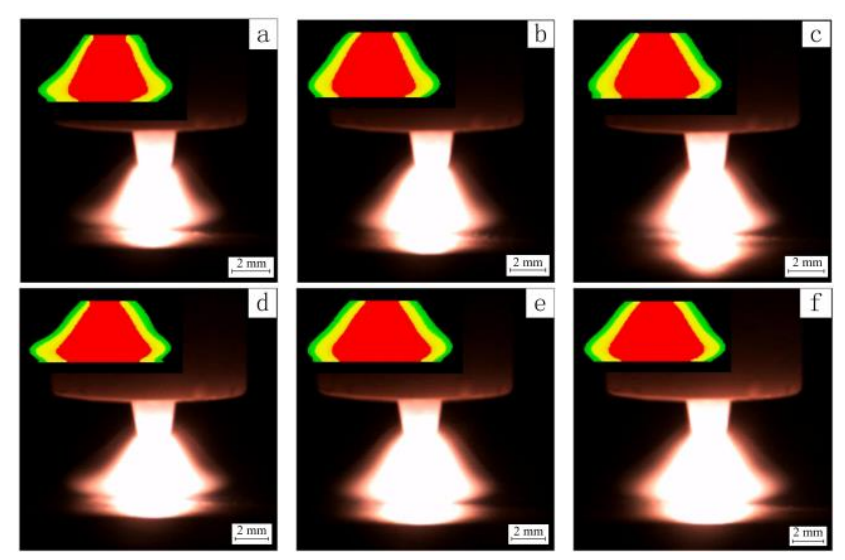

Fig. 6. Arc profiles captured by high-speed camera. Photographs $\mathrm{a}-\mathrm{f}$ are in correspondence with $1-6$ in Table 2 .

Table 4. Calculated size of region I and II

\begin{tabular}{|c|c|c|c|c|}
\hline No. & $S_{\mathrm{I}, \mathrm{mm}^{2}}$ & $S_{\mathrm{II}}, \mathrm{mm}^{2}$ & $R_{\mathrm{I}}, \%$ & $D_{\mathrm{I}}, \mathrm{mm}$ \\
\hline 1 & 15.12 & 23.72 & 38.9 & 4.24 \\
\hline 2 & 15.94 & 24.11 & 39.8 & 4.69 \\
\hline 3 & 16.63 & 24.32 & 40.6 & 4.76 \\
\hline 4 & 19.13 & 24.21 & 44.2 & 5.71 \\
\hline 5 & 20.99 & 25.93 & 44.7 & 5.97 \\
\hline 6 & 20.83 & 25.15 & 45.3 & 6.14 \\
\hline
\end{tabular}

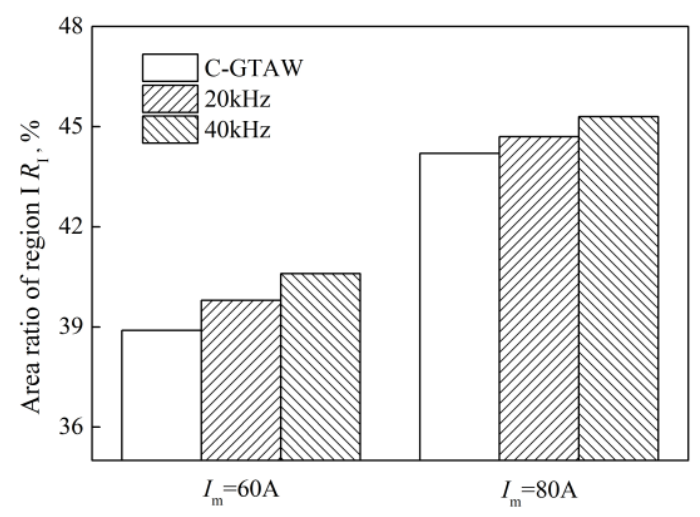

Fig. 7. Variation trends of the area ratio of core region I

\subsection{Arc force and arc pressure}

With average current of $60 \mathrm{~A}$ the influence of pulse frequency on the arc force is illustrated in Fig. 8, it needs to be pointed out that at each frequency arc force were measured three times and the value denoted by star symbol represents average arc force calculated from three tested results. As shown in Fig. 8, obvious increase over 30 percent was achieved by UHFP-GTAW process compared 
with that of C-GTAW $(f=0)$ process, and the higher the pulse frequency, the greater the average arc force. The maximum arc force occurs at frequency of $40 \mathrm{kHz}$, and increases by about $80.6 \%$ compared with that of C-GTAW.

Arc pressure can be calculated by Eq. 1:

$P_{\text {arc }}=F_{\text {arc }} /\left(\pi r^{2}\right)$,

where $P_{\text {arc }}$ is arc pressure, $F_{\text {arc }}=m g$ represents arc force ( $g=10 \mathrm{~N} / \mathrm{kg}$ ), and $r$ is radius of arc column melting metal of workpieces, i. e., half width of molten pool respectively. Considering that the width of the molten pool equals approximately to $D_{\mathrm{I}}$, so $r$ can be replaced by $0.5 D_{\mathrm{I}}$. Hence, Eq. 1 can also be expressed as Eq. 2.

$$
P_{\text {arc }}=\frac{m g}{\pi\left(0.5 D_{I}\right)^{2}} \text {. }
$$

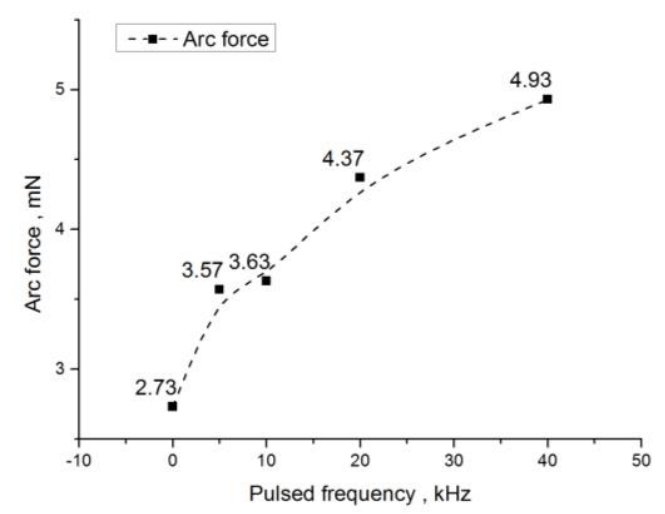

Fig. 8. Arc force at different pulsed current frequencies

As measured in Section 2.1, when average welding current adopted was $60 \mathrm{~A}$, corresponding to $0 \mathrm{kHz}, 20 \mathrm{kHz}$ and $40 \mathrm{kHz}$, projection diameter $D_{\text {I }}$ is $4.24 \mathrm{~mm}, 4.69 \mathrm{~mm}$ and $4.76 \mathrm{~mm}$ respectively. According to Eq. 2 arc pressure was calculated to be $193.4 \mathrm{~Pa}, 253.1 \mathrm{~Pa}$ and $277.2 \mathrm{~Pa}$ at C-GTAW, $20 \mathrm{kHz}$ and $40 \mathrm{kHz}$. It was obvious that arc pressure significantly increases when the pulsed current frequency is increased. Especially, arc pressure increases by $42.9 \%$ at $40 \mathrm{kHz}$ compared with that of C-GTAW process.

\subsection{Weld bead geometry and heat input efficiency}

The cross-sectional geometry of weld beads with average welding current at $80 \mathrm{~A}$ are shown in Fig. 9, which shows that weld penetration in the GTAW process is just $1.87 \mathrm{~mm}$, while in the UHFP-GTAW process weld penetration varies form $2.13 \mathrm{~mm}$ to $2.4 \mathrm{~mm}$ when the pulse frequency increases from $20 \mathrm{kHz}$ to $40 \mathrm{kHz}$. The depth-towidth ratio varying with different welding cases of C-GTAW, $20 \mathrm{kHz}$ and $40 \mathrm{kHz}$ follows a similar tendency to that of weld penetration. It can be concluded that UHFP-GTAW process has brought about a marked increase in weld penetration and depth-to-width ratio compared to GTAW process. It is supposed that larger arc pressure and more concentrated temperature distribution obtained by means of UHFP-GTAW process could result in digging effect on molten pool and improve the migration of molten pool liquid.
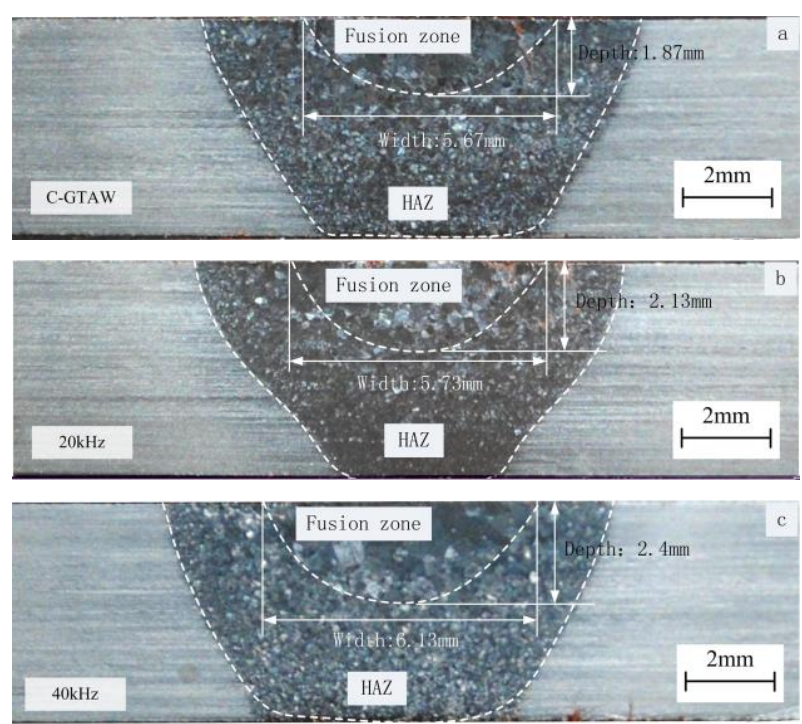

Fig. 9. Cross-sectional geometry of weld bead: a-C-GTAW; $\mathrm{b}-f=20 \mathrm{kHz} ; \mathrm{c}-f=40 \mathrm{kHz}$

Corresponding to the latter three sets of process parameters listed in Table 3, the mean currents are all the same value of $80 \mathrm{~A}$. It can be considered that the heat input of base metal obtained from welding arc is approximately equal under the three different process conditions. Thus the difference of weld shape can be attributed to the difference of heat input efficiency. The weld cross-sectional area is the direct reflection of heat input efficiency. In order to characterize heat input efficiency under different process conditions, image processing software named IMAGEPRO PLUS was used to calculate the weld cross-sectional area under different process conditions. Corresponding to C-GTAW, $20 \mathrm{kHz}$ and $40 \mathrm{kHz}$, the results calculated are $6.01 \mathrm{~mm}^{2}, 7.89 \mathrm{~mm}^{2}$, and $9.68 \mathrm{~mm}^{2}$ respectively. It can be concluded that heat input efficiency of UHFP-GTAW process is significantly higher than that of C-GTAW process, which led to cross-sectional area of the weld increased by at least $30 \%$ under the given experimental conditions.

\subsection{Weld bead microstructure}

Grain structure in fusion zone was subsequently observed and analyzed. Concentrated heat input from the arc to the molten pool makes fusion zone undergo rapid melting and solidification process. Fig. 10 shows crosssectional grain size and microstructure in fusion zone, which consists mainly of large-sized columnar crystalbased microstructure. Corresponding to C-GTAW, $20 \mathrm{kHz}$ and $40 \mathrm{kHz}$, average intercept of grain in fusion zone is $0.305 \mathrm{~mm}, \quad 0.240 \mathrm{~mm}$ and $0.210 \mathrm{~mm}$ respectively. In addition, grain size is reduced to $78.7 \%$ and $68.9 \%$ at $20 \mathrm{kHz}$ and $40 \mathrm{kHz}$ compared with that of C-GTAW process, which confirms that UHFP-GTAW process welded Ti-6Al-4V titanium alloy has the function of refining grain size and grain refinement becomes more significant with the increase of the pulse frequency.

Furthermore, microstructures were also observed by metallographic microscope with 100-times scale. Studies reported that, during welding process when the base metal is heated to temperatures over the $\beta$ transus temperature, martensite phase transformation from the high-temperature 
$\beta$ phase would take place, and $\alpha$ would be formed with basket-weave [18]. In the UHFP-GTAW process, $\alpha$ martensite appears in the form of short acicular within the prior- $\beta$ grains, and the distribution of basket-weave structure was also found to be expanded in fusion zone, which is particularly obvious with frequency of $40 \mathrm{kHz}$. By contrast, however, there was barely any basket-weave structure in fusion zone welded by C-GTAW process.
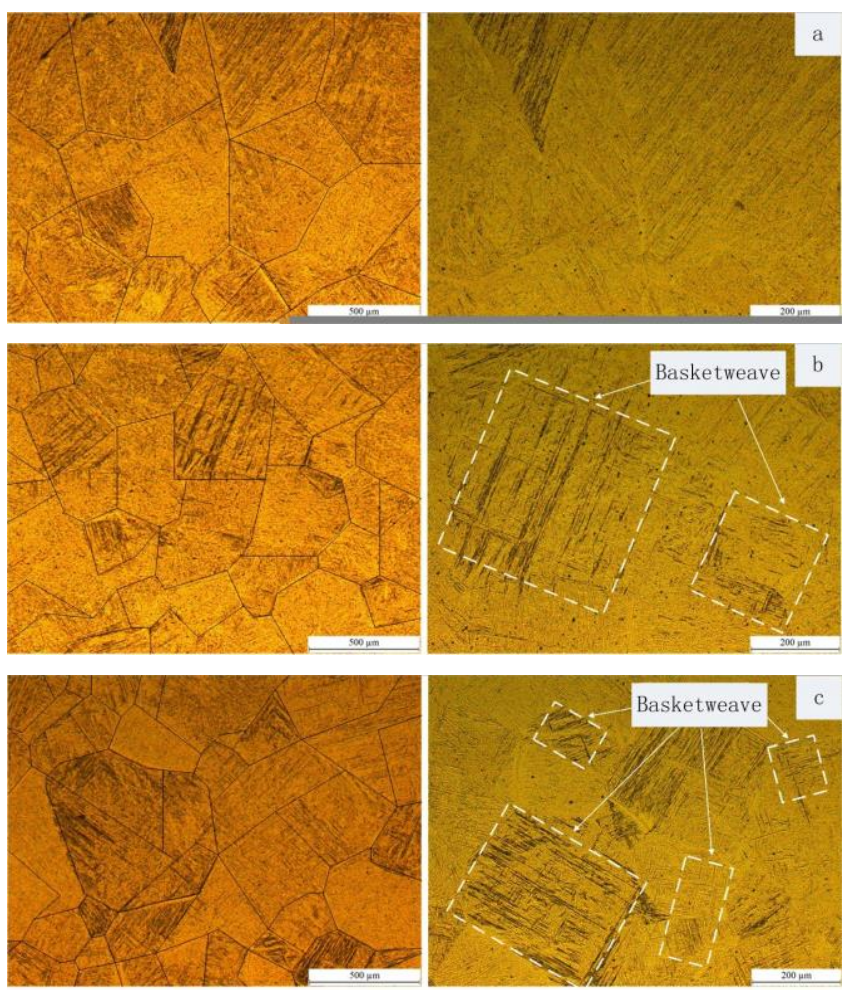

Fig. 10. Grain size and microstructure of fusion zone: $\mathrm{a}-\mathrm{C}-\mathrm{GTAW}$ process; $\mathrm{b}-f=20 \mathrm{kHz} ; \mathrm{c}-f=40 \mathrm{kHz}$

\subsection{Discussion}

As shown in Fig. 11, arc pressure is primarily composed of electromagnetic pressure $\left(p_{\mathrm{e}}\right)$ and plasma jet pressure $\left(p_{\mathrm{p}}\right)$. The former is produced by the hybrid interaction effect between welding current and its selfinduced electromagnetic field, while the latter is created by plasma motion due to the current density difference from tungsten tip (point A) to surface of workpiece (point B). It has been proved that pinch effect of arc column is initiated by electromagnetic force increment [19], and pulsed current with ultra-high frequency has the advantage of enhancing pinch effect. Radial component of electromagnetic force makes electric streamline close to the axis of the arc, while axial component of electromagnetic force will enlarge axial pressure exerting to molten pool.

During UHFP-GTAW process the core region of arc profile representing the high-temperature area of arc column would expand as average welding current increases. Besides, the higher the pulsed frequency, the larger the core region area. The reason for this is that higher pulse frequency make core region of arc column possess more concentrated heat input, and then more charged particles would be ionized, which increases the kinetic energy of arc plasma resulting in larger plasma jet force. With the increase of axial electromagnetic force and axial plasma jet force, the degree of depression on the surface of molten pool will be aggravated, thus larger weld depth and higher depth-to-width ratio can be obtained.

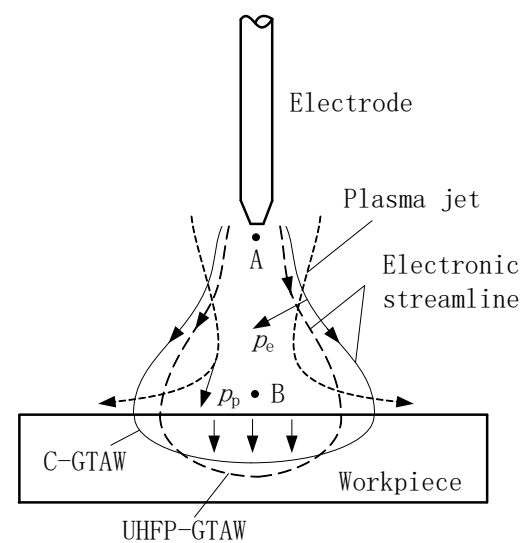

Fig. 11. Mechanism description of arc characteristics

Experimental results show that grain refinement occurred obviously in UHFP-GTAW process, and more basket-weave structure were also obtained, which helps to improve fracture toughness and fatigue properties of titanium alloy. It is analyzed that, during UHFP-GTAW process pulsed current makes the energy and the arc force exerting to the molten pool change periodically. the cyclic variations of energy would cause thermal fluctuations of molten pool which results in periodic interruption in the solidification process. Furthermore, the shape of molten pool takes on continual change, and hence the fluid motion and the convective of molten pool are also enhanced. The continual change in weld pool shape and the periodic interruptions in the growth process appear to inhibit the increase of crystallite size and lead to the refinement of the $\beta$ grain structure. On the other hand, studies show that $\beta$ grains tend to grow in the direction of the heat flow during the solidification process [18]. During UHFP-GTAW process arc force with strong stirring effect on the molten pool make the direction of heat flow irregular change, and thus the growth of each grain has not obvious orientation. As a result, each grain grows only a short distance, while more grains grow, which also leads to grain refinement to some extent. In addition, the enhanced fluid flow in UHFPGTAW process decreases thermal gradient and reduces the cooling rate, which supposed to be the reason $\alpha$ martensite appears in the form of short acicular arranged in a crisscross pattern and wider distribution of basket-weave structure in fusion zone.

\section{CONCLUSIONS}

1. Compared with C-GTAW process, UHFP-GTAW process makes heat input more concentrated and leads to higher heat input efficiency, which can expand the core area of arc column with high temperature.

2. UHFP-GTAW process can produce larger arc pressure which can be increased by $42.9 \%$ with pulse frequency at $40 \mathrm{kHz}$ compared with that of C-GTAW process. Furthermore, the depth-to-width ratio enlarges with the increase of welding frequency.

3. Grain size is refined and reduced to $78.7 \% \sim 68.9 \%$ 
in UHFP-GTAW process compared with that of C-GTAW process. Meanwhile, distribution of basketweave structure expands in the fusion zone of Ti-6Al-4V titanium alloy welded by means of UHFP-GTAW process.

\section{Acknowledgments}

This research is supported by the National Natural Science Foundation of China under grant No. 51675052. We acknowledge and thus sincerely appreciate Beijing Institute of Petro-chemical Technology's substantial supports.

\section{REFERENCES}

1. Jha, A.K., Singh, S.K.,

Kiranmayee, M.S., Sreekumar, K., Sinha, P.P. Failure Analysis of Titanium Alloy (Ti6Al4V) Fastener Used in Aerospace Application Engineering Failure Analysis 17 (6) 2010: pp. $1457-1465$.

https://doi.org/10.1016/j.engfailanal.2010.05.007

2. Cotton, J.D., $\quad$ Briggs, R.D., $\quad$ Boyer, R.R., Tamirisakandala, S., $\quad$ Russo, P., $\quad$ Shchetnikov, N., Fanning, J.C. State of the Art in Beta Titanium Alloys for Airframe Applications $\quad$ JOM 67 (6) 2015: pp. $1281-1303$.

https://doi.org/10.1007/s11837-015-1442-4

3. Ivasishin, O.M., Anokhin, V.M., Demidik, A.N., Savvakin, D.G. Cost-Effective Blended Elemental Powder Metallurgy of Titanium Alloys for Transportation Application Key Engineering Materials 188 2000: pp. $55-62$.

https://doi.org/10.4028/www.scientific.net/KEM.188.55

4. Zreiqat, H., Valenzuela, S.M., Nissan, B.B., Roest, R., Knabe, C., Radianski, R.J., Renz, H., Evans, P.J. The Effect of Surface Chemistry Modification of Titanium Alloy on Signalling Pathways in Human Osteoblasts Biomaterials 26 (36) 2005: pp. 7579-7586.

https://doi.org/10.1016/j.biomaterials.2005.05.024

5. Köse, C., Karaca, E. Effect of Pre and Post Weld Heat Treatments on the Microstructure and Mechanical Properties of Fiber Optic Beam Delivery System Assisted Robotic Nd: YAG Laser Welded Ti-6Al-4V Alloy Archives of Metallurgy and Materials 63 (3) 2018: pp. 1225-1233. https://doi.org/10.24425/123795

6. Balasubramanian, M., Jayabalan, V., Balasubramanian, V. Developing Mathematical Models to Predict Tensile Properties of Pulsed Current Gas Tungsten Arc Welded Ti-6Al-4V Alloy Materials \& Design 29 (1) 2008: pp. $92-97$. https://doi.org/10.1016/j.matdes.2006.12.001

7. Balasubramanian, M., Jayabalan, V., Balasubramanian, V. Effect of Pulsed Gas Tungsten Arc Welding on Corrosion Behavior of Ti-6Al-4V Titanium Alloy Materials \& Design 29 2008: pp. 1359-1363. https://doi.org/10.1016/j.matdes.2007.06.009

8. Sundaresan, S., $\quad$ Ram, G.D.J., $\quad$ Reddy, G.M. Microstructural Refinement of Weld Fusion Zones in $\alpha-\beta$
Titanium Alloys using Pulsed Current Welding Materials Science \& Engineering A $262(1-2)$ 1999: pp. 88-100. https://doi.org/10.1016/S0921-5093(98)01010-7

9. Balasubramanian, M., Jayabalan, V., Balasubramanian, V. Effect of Pulsed Current Gas Tungsten Arc Welding Parameters on Microstructure of Titanium Alloy Welds Journal of Manufacturing Science \& Engineering 131 (6) 2009: pp. 751-760. https://doi.org/10.1115/1.4000373

10. Kumar, T.S., Balasubramanian, V., Sanavullah, M.Y. Influences of Pulsed Current Tungsten Inert Gas Welding Parameters on the Tensile Properties of AA 6061 Aluminium Alloy Materials \& Design 28 (7) 2007: pp. 2080-2092. https://doi.org/10.1016/j.matdes.2006.05.027

11. Balasubramanian, M. Prediction of Optimum Weld Pool Geometry of PCTIG Welded Titanium Alloy using Statistical Design Engineering Science Technology, an International Journal 19 (1) 2016: pp. 15-21. https://doi.org/10.1016/j.jestch.2015.06.001

12. Ge, Z.X., Chen, H.M., Ge, Y. Affection of Arc-weld Inversion Power's Frequency on Weld Grain's Thinning Hot Working Technology 7 2004: pp. 47-48. https://doi.org/10.14158/j.cnki.1001-3814.2004.07.021

13. Balasubramanian, M., Ravisankar, V., Reddy, G.M. Effect of Pulsed Current Welding on Mechanical Properties of High Strength Aluminum Alloy International Journal of Advanced Manufacturing Technology 36 (3) 2008: pp. $254-262$. https://doi.org/10.1007/s00170-006-0848-0

14. Babu, N.K., Raman, S.G.S. Influence of Current Pulsing on Microstructure and Mechanical Properties of Ti-6Al-4V TIG Weldments Science and Technology of Welding and Joining 11 (4) 2006: pp. 442-447. https://doi.org/10.1179/174329306X120750

15. Qi, B.J., Xu, H.Y., Zhou, X.G., Huang, S.T. Fast Transform Ultra-sonic Pulse TIG Welding Transactions of the China Welding Institution 30 (7) 2009: pp. 57-60. https://doi.org/10.3321/j.issn:0253-360X.2009.07.015

16. Qi, B.J., Yang, Z., Yang, M.X., Cong, B.Q. Analysis on Characteristic of Ultra High Frequency Pulsed Gas Tungsten Arc Welding Process Journal of Mechanical Engineering 52 (2) 2016. pp. 26-32. https://doi.org/10.3901/JME.2016.02.026

17. Qi, B.J., Yang, M.X., Cong, B.Q., Liu, F.J. The Effect of Arc Behavior on Weld Geometry by High-frequency Pulse GTAW Process with 0Cr18Ni9Ti Stainless Steel The International Journal of Advanced Manufacturing Technology $66(9-12)$ 2013: pp. 1545-1553. https://doi.org/10.1007/s00170-012-4438-z

18. Köse, C., Karaca, E. Robotic Nd:YAG Fiber Laser Welding of Ti-6Al-4V Alloy Metals 7 (6) 2017: pp. $221-231$. https://doi.org/10.3390/met7060221

19. Ando, K., Hasegawa, M. Welding Arc Phenomenon, China Mechine Press, 1985: pp. 249-250. 